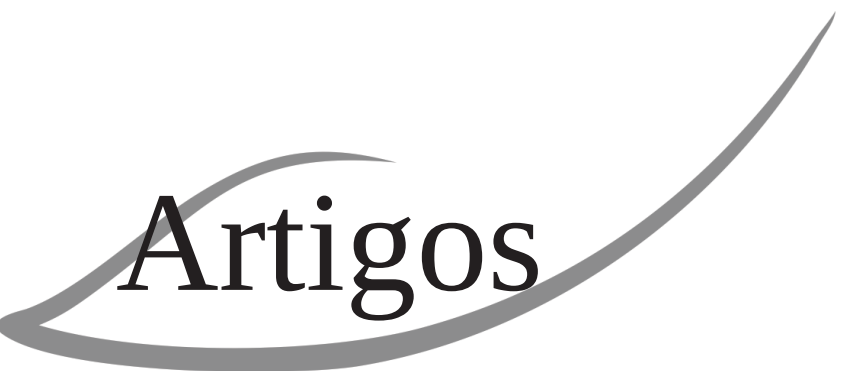




\section{A escola como instituição: primeiras aproximações}

\section{The school as an institution: first approximations}

Beatriz Gomes Nadal*

Resumo: O objetivo do presente trabalho é desenvolver uma reflexão acerca do conceito de instituição escolar com base nos estudos genealógicos de instituição de René Lourau (1996). Por meio de uma revisão teórica, problematiza a relação dialética entre as dimensões universal, singular e particular que constituem as instituições e o modo como estas podem configurar maior ou menor dinamicidade. O artigo aponta que as instituições são construções históricas e humanas, constituídas de elementos ideológicos (ideias), econômicos (estrutura e funcionalidade) e políticos (ação humana intencional), sendo, portanto, instâncias instituintes e capazes de constituir uma realidade própria e influenciar a realidade social.

Palavras-chave: Instituição. Escola. Escola como instituição. Lourau.

Abstract: The objective of this study is to develop a reflection on the concept of the school based on René Lourau's genealogical studies (1996). Through a theoretical review, a discussion is provided of the dialectical relationships between the universal, unique and particular dimensions of institutions and how they can set higher or lower dynamics. The article points out that institutions are human and historical constructions, consisting of elements that are ideological (ideas), economic (structure and function) and political (intentional human action), and are therefore capable of constructing their own reality and influencing social reality.

Keywords: Institution. School. School as institution. Lourau.

\section{Introdução}

A instituição é lance de luta para a reforma social.

Lapassade e Lourau, 1972

O reconhecimento da força da escola na construção da realidade educativa tornou urgente sua compreensão, motivando pesquisas nos campos de currículo e didática, formação de professores, e política e gestão educacional a se entrelaçarem na busca de sua identidade institucional, do cotidiano organizacional e dos movimentos internos e particulares que tornam a escola uma realidade obscura e ainda pouco dominada.

A escola possui uma especificidade enquanto dimensão organizadora do conjunto complexo de processos que ali se desencadeiam. Trata-se de uma instância com dinâmica própria que merece ser desvelada.

A inferência que fazemos - de que a escola é uma instituição educativa que se constitui pela participação e influência de

\footnotetext{
${ }^{1}$ Doutora em Educação: Currículo pela PUC-SP. Professora da Universidade Estadual de Ponta Grossa (UEPG). E-mail: <beatriznadal@uepg.br>.
} 
outras instâncias e sujeitos - remete à questão: Qual é a natureza institucional da escola? Como ela se configura?

\section{Primeiras aproximações à ideia de escola}

A dimensão material da escola - professores e alunos ensinando e aprendendo, espaços escolares tais como salas de aula, bibliotecas, laboratórios, pátios e quadras é, naturalmente, a primeira que se nos apresenta e remete à função desta instituição na sociedade. Trata-se de uma visão primeira, próxima da lógica oficial, como explicitada por Schmidt (1989, p. 12):

[A] escola é uma instituição social, historicamente considerada, inserida numa certa realidade na qual sofre e exerce influência. Não é uma instituição neutra perante a realidade social. Deve organizar o ensino, de forma a considerar o papel de cada indivíduo e de cada grupo organizado dentro da sociedade. Sua função, portanto, é preparar o indivíduo proporcionando-lhe o desenvolvimento de certas competências exigidas pela vida social. É também dar-lhe uma compreensão da cultura e uma 'visão de mundo' e prepará-lo para [a] cidadania. [...] Assim, a educação escolar é caracterizada por ser uma atividade sistemática, intencional e organizada - organizada no que diz respeito aos conteúdos, e sistemática no que se relaciona aos métodos que utiliza.

Vemos na autora o apontamento de elementos centrais para a compreensão da escola, como sua função social, seu modo de estar organizada e o trabalho que cumpre; e, ao mesmo tempo, a afirmação de que a escola não apenas recebe como também exerce influência social por meio de um papel que não é neutro, mas intencional e político, já que a partir de suas escolhas contribuirá para a construção de uma dada sociedade.

Porém, uma compreensão ampliada da escola, enfocando-a para além daquilo que está materialmente visível ou simbolicamente representado, pode ser capaz - ao captar a ação dos sujeitos em relação direta com a estrutura e função social estabelecidas - de reconhecer na escola não apenas outras dimensões como, também, uma dinâmica própria.

Tardif e Lessard (2005, p. 55), por exemplo, tomam a escola como "um espaço sócio-organizacional no qual atuam diversos indivíduos ligados entre si por vários tipos de relações, mais ou menos formalizadas, abrigando tensões, negociações, colaborações, conflitos e reajustamentos circunstanciais ou profundos de suas relações”. Para os autores, a ideia de escola não exclui aquilo que socialmente lhe está colocado, pois ao mesmo tempo que os processos em seu interior são, de certo modo, formalizados também ocorrem movimentos de natureza intensa e contraditória de aceitação ou negação, de flexibilização do que foi formalizado, movimentos estes que podemos reconhecer como sendo próprios do "humano".

Num texto clássico da sociologia, Cândido (1973, p. 107) afirma que a escola

[...] é algo mais amplo, compreendendo não apenas as relações ordenadas conscientemente, mas [...] todas as que derivam da sua [própria] existência como grupo social, o que representa dizer que há relações que vão além daquilo que se estabelece para ela externamente, pois nascem da própria dinâmica do grupo social escolar.

O modo como este autor percebe a escola aproxima-se muito da elaboração de Tardif e Lessard, pois também neles encontra-se a intenção de forjá-la como espaço de 
construção dinâmica, associada à ideia do humano que permeia o fazer educativo. Essa dimensão mostra-se clara quando o autor fala que na escola há o existir e a existência, a vida.

Gomes (2005, p. 284), por sua vez, argumenta que a escola:

Não [é] como um tipo ideal de burocracia, que funciona de modo estritamente racional, à semelhança de um relógio, mas como organização flexivelmente articulada. Composta de salas de aula que se relacionam com uma unidade de atividades-meio (a administração), cada professor dispõe de relativa independência e visibilidade de classe. Deste modo, decisões tomadas num segmento não são aplicadas automaticamente em outros.

Ao apontar a existência de duas instâncias diferenciadas na instituição escolar a pedagógica, representada pelos professores e salas de aula, e a administrativa, composta pelos gestores e espaços de administração - e ao afirmar a relativa independência dos professores em seu trabalho, o autor contribui para que se perceba nas escolas um movimento interno e próprio, possivelmente desencadeado por resistências, releituras, flexibilizações ou adaptações que decorrem justamente desta margem de autonomia docente.

Outra conceituação possível nessa mesma linha, que procura mostrar que a dinâmica interna se dá a partir de segmentos diferenciados, é a de Alarcão (2003, p. 81), para quem a escola se situa

[...] no mesocosmos e estabelece a interface entre a sociedade adulta e as crianças e jovens em desenvolvimento. Como sistema local de aprendizagem, situa-se num território específico, desenvolve sua dinâmica própria, sem, contudo, perder a ligação que a prende ao grande sistema de educação nacional e internacional.
A escola surge-nos como um todo e não como um ajuntamento de pessoas. Esse todo, para ser coeso e dinâmico, exige uma organização. Em resumo, a escola é uma comunidade social, organizada para exercer a função de educar e instruir.

Alarcão (2003) argumenta que a escola é uma instância educativa específica, dentre outras existentes. Designa o espaço escolar como meso por entender que ele está no meio, entre a sociedade (educadora) e a geração que precisa aprender para estar inserida em tal sociedade. Todavia, não se trata de uma visão fragmentária sobre a escola (até porque a relação entre os níveis macrossocial e micropessoal é afirmada), mas do reconhecimento da singularidade organizacional e funcional da instituição. A ideia de comunidade social organizada implica também no reconhecimento da especificidade e da dinâmica própria da dimensão meso.

Destaque ao papel formativo da escola como instância mediadora é dado também por Pérez Gómez (2001, p. 273), que define a escola como

[...] espaço ecológico integrador dos diferentes contextos de produção, utilização e reprodução de conhecimento [...], [um] centro de vivência e recriação da cultura, utilizando a cultura crítica para provocar a reconstrução pessoal da cultura experiencial dos estudantes.

Além de indicar que a função social da escola está relacionada ao trabalho com os conhecimentos, o autor aponta o dinamismo da instituição quando mostra que tal função é exercida a partir de movimentos de reconstrução da cultura, os quais tornam a escola um "centro de vivência e recriação". A reconstrução da cultura, produzida pelo confronto entre as culturas crítica e experiencial dos alunos, pressupõe 
posicionamento, debate e problematização e estes, por sua vez, estão no centro do movimento institucional.

Forquin (1993, p. 167), por sua vez, também discorre sobre a dimensão simbólica presente na ideia de escola ao defini-la como um "[...] mundo social, que tem suas características de vida próprias, seus ritmos e seus ritos, sua linguagem, seu imaginário, seus modos próprios de regulação e transgressão, seu regime próprio de produção e de gestão de símbolos”. Afirma-se aí a existência de uma rede simbólica que não é dada e definitiva. A capacidade dos sujeitos que compõem a escola de ir além do estabelecido é demonstrada pelo autor ao afirmar que existem movimentos de criação através do imaginário, da regulação e da própria transgressão de sentidos.

Em conjunto, as definições de escola permitem percebê-la em duas dimensões: uma oficial e formal, dada, ligada à sua função social; e outra obscura e em constante construção, relacionada ao modo pelo qual os sujeitos vivem a tarefa educativa por meio da organização escolar. A problemática que envolve o desvelamento da instituição escolar exige, então, compreender o cenário, fatos e demandas que a originaram e que a constituem cotidianamente em face de seu trabalho na sociedade. Exige captá-la através da relação entre seus múltiplos determinantes e a complexidade de sua prática.

\section{A dinâmica escolar: a escola instituída e instituinte}

A escola é, ao mesmo tempo, uma realidade dada e dinâmica, uma organização em permanente construção e constituição, ideia que implica no envolvimento do sujeito histórico que, através de sua realidade socioeconômica, política, cultural e organi- zacional, desenvolve uma visão de mundo, uma consciência e ética (sua pessoalidade), e constrói, em coletividade, uma dada realidade. Tal premissa introduz um novo tema à discussão, relativo ao papel dos sujeitos na instituição.

De acordo com Ardoino e Lourau (2003), os sujeitos podem se posicionar como agentes, atores e autores. Ao se pensar o funcionamento organizacional, a ideia de agente é a que primeiro surge, pois se refere a determinado posto ou posição previstos, em termos de função, dentro de uma dada estrutura organizacional. A ideia de ator, por sua vez, está em relação direta com a de agente, mas a extrapola: ator é aquele, efetivamente, que exerce a prática para a qual está destinado e o faz a partir de sua própria epistemologia. Talvez se possa dizer que institucionalmente ele é ator; organizacionalmente, é agente.

A caracterização dos sujeitos como agentes e atores se assenta numa lógica de caráter histórico, temporal e social (cumpre um trabalho idealizado, dele esperado); organizacional (em funções previamente definidas no quadro da organização); e até mesmo biológico (consciência sobre seu fazer, planejando e definindo metas em correlação com a estrutura maior).

À posição de agente e ator acrescenta-se uma terceira: a de autor. No entanto, o fato de que o sujeito age numa situação estabelecida, gerenciando seus conhecimentos, não o torna, necessariamente, autor.

$\mathrm{O}$ ator executa (enquanto tal, ele permanece agido, a não ser quando 'estraga' algo voluntariamente, ou ao menos 'intencionalmente', sem que sempre tenha disso clara consciência), ele atua e interpreta sua partitura ou seu texto. Decerto acrescenta mais, ou menos, à obra inicial, mas não se torna a origem (o autor) ou uma das origens possíveis. (ARDOINO; LOURAU, 2003, p. 21) 
A autoria surge quando há espaços para criar e propor, para participar dos processos decisivos em diferentes instâncias. O autor é o criador de uma realidade; ele a estabelece, engendra, arquiteta e, por fazê-lo, é reconhecido em sua condição de criador perante seus pares. O agir com autoria é perpassado de relativa autonomia e capacidade de proposição em função de um projeto educativo de escola. Para além dos campos já mencionados, relativos ao agente e ao ator, a noção de autor implica também a ética, pois ele é um sujeito de escolhas e definições que repercutem sobre os pares e o contexto. A noção de autoria transforma, também, a de autorização:

a autorização se torna o fato de se autorizar, isto é, a intenção, e a capacidade conquistada, de se tornar seu próprio coautor, de querer se situar explicitamente na origem dos próprios atos e, em conseqüência, na origem de si mesmo enquanto sujeito. $\mathrm{O}$ autor reconhece, assim, tanto a legitimidade como a necessidade de decidir certas coisas por si mesmo. (ARDOINO; LOURAU, 2003, p. 20)

O autor, portanto, vê-se como sujeito de sua própria prática, agindo e concretizando trabalhos e processos não por mera delegação ou atribuição, mas porque se sente e deseja ser um realizador participante, uma vez que a partir de seu próprio espaço é capaz de sentir, perceber e perspectivar a realidade institucional e organizacional de modo diferente.

Assim, se a primeira questão - relativa à natureza da escola - nos mostra que ela é uma dinâmica, o entendimento sobre a possibilidade de os sujeitos se constituírem como autores é fundamental para que possamos refletir sobre a segunda questão, relativa aos movimentos internos e específicos que põem a escola em movimento e a tornam uma construção com traços bastante específicos.
A perspectiva dos papéis que os sujeitos assumem através de sua condição tríptica - como agentes, atores e autores - fundamenta em partes o entendimento da origem histórica dos movimentos na escola. São os processos (as percepções, as compreensões, os sentidos atribuídos, o modo como o trabalho é realizado, as alterações entre o estabelecido e o vivido, as ações desencadeadas, as novas propostas e soluções encontradas) e as realidades construídas (com menos intensidade por alguns, que procuram manter-se naquilo que lhes foi estabelecido e definido ou com mais intensidade por outros, que ao vislumbrar diferentes significados, necessidades e possibilidades buscam alterar o universo escolar constituído) pelos sujeitos - ora agentes e atores, ora agentes e autores que permitem à escola colocar-se em movimento. A dinâmica da realidade não pode ser explicada se dela se excluir aquilo que é o fator mais construtivo: o elemento humano.

Desse modo, ao afirmar que a escola é uma realidade única, em permanente caracterização e construção, estamos a dizer que ela não está apenas "posta”, “dada” ou “definida”, mas que se constrói cotidianamente pelas interações e ações entre/dos sujeitos a partir de um contexto histórico e concreto.

Trata-se de compreender que a escola é, ao mesmo tempo, uma realidade instituída e instituinte; realidade concreta, efetiva e estabelecida, mas também, simultaneamente, processo e dinâmica, refazendo-se a partir de sua própria história e trajetória por meio da ação dos sujeitos e grupos. Trata-se de dois conceitos extremamente próximos aos de agente, ator e autor que, juntos destes, permitem caracterizar a escola e compreender seu movimento.

De acordo com o Dicionário Houaiss (2004, p. 1627) a palavra "instituído" significa "1. que se instituiu 2. JUR em cujo favor 
se institui um benefício ou direito (diz-se do indivíduo) q ETIM part. de instituir". "Instituinte”, por sua vez, é um vocábulo não dicionarizado, mas que possui um correlato, "instituidor", o qual significa: "que ou aquele que institui; instaurador, estabelecedor, iniciador q ETIM lat. institūtor,ōris 'autor, fundador'." Os vocábulos "instituído" e "instituinte/instituidor" têm, então, suas raízes na ideia de instituir algo, ser autor, o que remete à de criação, de criar algo.

A dimensão instituída pode ser identificada com normas sociais e sistemas de valores convencionados em relação ao que se espera que a educação seja. A dimensão instituinte, por sua vez, caracteriza-se pelo movimento e vida dos sujeitos e grupos nas instituições, pois, movidos por suas necessidades, convicções e objetivos, eles constroem uma realidade específica e alteram parte do que está instituído.

\section{A escola como instituição}

A compreensão da dinâmica institucional da escola pode ter como base os estudos de Lourau (1996), os quais se caracterizam pela construção de uma genealogia da instituição, trabalho que realizou desenvolvendo análise pormenorizada em clássicos da filosofia do direito, do marxismo e da sociologia.

A ideia de instituição associa-se às de norma universal, de fundação ou constituição oficial ou política de algo, de organização material ou jurídica. A instituição é uma norma universal na medida em que estabelece modelos de comportamento, regras, noções, padrões e valores que funcionarão buscando regular as atitudes e ações dos sujeitos. Nessa lógica, podemos entender que o sistema de educação via escola é uma norma universal da qual decorrem noções como escola, aluno, aprendizagem, avaliação, aprovação...

A educação precede a criação do sistema educacional. A instituição escolar é criada na medida em que a sociedade sente a limitação da educação realizada no interior das famílias e da comunidade e vê a necessidade de educar as crianças não apenas em relação à aprendizagem da moral, da religião e da profissão, mas também para a aprendizagem do conhecimento que decorre das ciências. Logo, a sociedade busca instituir a escola na medida em que lhe atribui e encomenda uma função e lhe atribui uma existência oficial, jurídica e material.

Assim, a norma universal e a constituição oficial da escola implicaram no estabelecimento de uma dada organização (jurídica, material, de recursos) que viabilizasse o trabalho a ser feito e o ideal a ser alcançado, dotando a instituição de uma "forma social visível” (LOURAU, 1996). Essa forma, ao mesmo tempo que apresenta uma dada racionalidade face à função social esperada, também a nega ou contradiz. Além disso, nem tudo aquilo que se estabelece ideal, oficial e formalmente se efetiva tal e qual pensado, pois essa concretização se faz por meio de homens que, numa condição histórica, também produzem movimentos de negatividade, forjando a instituição de um modo particular. Essa complexidade inerente às instituições levou o autor a buscar analisá-las dialeticamente. Assim, para Lourau, a instituição se constitui pelo movimento dialético entre os três momentos que a compõe: universal, singular e particular.

O momento da universalidade é o da unidade positiva do conceito. Nesse momento é que o conceito é plenamente verdadeiro, a saber, verdadeiro abstratamente, geralmente. Em abstrato, o 
salário e a família são normas universais da sociedade, fatos sociais positivos. Mas somente no plano abstrato. (LOURAU, 1996, p. 10)

O momento universal da instituição tem a ver com a ideia de norma social. Por se referir a princípios, definindo o que deve ser feito, a dimensão universal representa um conjunto de sentidos, significados, valores, formas de proceder que "dizem" a instituição na medida em que explicitam sua finalidade ou função oficial e os processos que lá se desenvolverão (no caso da instituição escolar, a socialização e formação de crianças e jovens). É a ideologia que está posta e circula não apenas no espaço organizacional da instituição, mas partilhada pela sociedade como um todo.

Desse modo, enquanto momento universal a escola é a instituição na qual se efetivam processos educativos formais em torno de conhecimentos historicamente produzidos e acumulados, visando ao desenvolvimento das capacidades humanas, à preparação para a cidadania e ao exercício de papéis sociais. Há um eixo da referência institucional: a ideia, universalmente aceita, de que é na escola que se dá a educação formal.

O momento universal da escola é abstrato e é isto o que lhe permite ser uma verdade plena, já que enquanto ideia a instituição se mantém em seu plano ideal e perfeito, numa condição de positividade.

O momento ou dimensão universal da escola encontra-se sempre em relação dialética de negatividade com seu polo de oposição, o momento da particularidade.

Com efeito, o momento da particularidade exprime a negação do momento precedente. Assim é que, em nossas sociedades regidas pelo trabalho assalariado e pelo casamento, um indivíduo pode ser não assalariado e solteiro [...] Toda verdade geral deixa de ser tal plenamente desde que se encarna, se aplica em condições particulares, circunstanciais, determinadas, isto é, no grupo heterogêneo e variável dos indivíduos diferentes pela origem social, idade, sexo e posição. Não se pode portanto confundir universalidade com totalidade. A universalidade traz em si mesma sua contradição. Toda ideia é tão ‘verdadeira’ quanto sua contrária, não em geral, conforme pretende o cepticismo, mas desde que se encarna na ação dos indivíduos e das coletividades. (LOURAU, 1996, p. 10)

A dimensão particular diz respeito aos sujeitos, ao elemento humano que, ao mesmo tempo que partilha e reproduz (parcialmente) a realidade universal socialmente convencionada, também atua sobre ela de modo relativamente autônomo e pessoal, negando-a, flexibilizando-a, adaptando-a, alterando-a. Isso significa que aquilo que idealmente deveria ser (enquanto verdade positiva) pode vir a não sê-lo na medida em que é retrabalhado por uma figura essencialmente particular: o humano (unidade negativa).

O particular representa, então, vida e movimento, dinâmica e complexidade por possibilitar a recriação em relação ao universal, o qual não acata ou reproduz passivamente, mas altera a partir de fatores identitários, como a classe social, os conhecimentos que possui, o sexo, a idade, a historicidade...

$\mathrm{Na}$ escola, o momento particular se apresenta por meio da ação instituída, mas também instituinte, dos indivíduos em relação às verdades ou premissas "universalmente aceitas" e a eles colocadas; esses princípios universais são referendados, flexibilizados ou negados. Assim, pode-se dizer que é norma universal que a educação escolar educa e ensina as crianças e que, apesar disto, as ações educativas particulares 
contrariam esse princípio universal quando a escola não ensina ou não consegue ensinar, ou quando exclui e marginaliza em vez de incluir e integrar.

Por fim, há um terceiro desdobramento da instituição, seu momento singular:

E, entretanto, a sociedade funciona, bem ou mal, porque as normas universais, admitidas como tais, não se encarnam diretamente nos indivíduos, mas passam pela mediação de formas sociais singulares, de modos de organização mais ou menos adaptados a uma delas ou a funções. O momento da singularidade é o momento da unidade negativa, resultante da ação da negatividade sobre a unidade positiva da norma universal. (LOURAU, 1996, p. 10)

A ação dos sujeitos particulares (polo negativo) em relação ao universal (polo positivo) se desencadeia mediada e organizada por uma terceira dimensão que também opera negatividade: o singular.

O momento singular corresponde à forma social, à organização, aos formatos que a instituição assume em termos jurídicos, físicos e de funcionamento. Corresponde à estrutura jurídica (o estabelecimento de ensino juridicamente criado, as legislações que normatizam finalidades, processos e procedimentos); física (o espaço escolar, o prédio, a mobília e recursos disponíveis); e organizacional (o organograma da escola e a forma como este define os papéis e respectivas atribuições e funções; os processos de gestão adotados; a composição curricular, dos espaços e tempos).

Trata-se de uma dimensão que contextualiza e regula localmente a ação dos sujeitos e grupos, dando-lhes determinadas formas; também organiza os trabalhos da/na instituição. É também o formato pelo qual o universal busca se concretizar e mostrar-se material e simbolicamente visível. Ardoino e
Lourau (2003, p. 18) contribuem para a compreensão do singular:

O estabelecimento são os muros, os locais, o mobiliário, tangíveis e visíveis, os agentes com, caso necessário, o uniforme que vestem, atestando o pertencimento ao aparelho. São, ainda, as estruturas da organização, a hierarquia, os horários, o emprego do tempo, os regulamentos - já menos evidentes, mais abstratos, porém, apesar de tudo, perceptíveis porque explicitamente significados, afixados, codificados (escritos, graduações, galões, atitudes mais ou menos sistematizadas, estatutos etc.)

Ao mesmo tempo que a ideia de educação escolar tornou-se uma convenção universalmente aceita, uma norma social (a escola educa e ensina as crianças), estruturou-se uma organização (prédios, horários, conteúdos, funções, modelos de funcionamento, normas) que, contudo, não a traduziu fielmente na medida em que também atua sobre ela com negatividade.

Universal, particular e singular são, dessa forma, três desdobramentos ou dimensões da instituição que se apresentam dialeticamente unidas. Sua dissociação como segmentos separados só é possível teoricamente, pois a cisão entre os momentos impediria uma compreensão real e efetiva da realidade escolar, já que a ação dos sujeitos particulares sobre a dimensão universal nunca é direta, mas sempre mediada e estruturada pela dimensão singular, conforme alerta Lourau (1996, p. 10-11):

É comum confundir-se particularidade e singularidade, opondo-se artificialmente o geral (o universal) ao particular, esquecendo que esta oposição é puramente abstrata, não existe nunca na prática, mas somente na ideologia e na filosofia idealista. Com isso, o que fica obliterado é o terceiro momento do conceito de instituição e, fato 
mais grave ainda, a ação recíproca dos três momentos, sem a qual não há dialética. Com a oposição do particular ao geral a dialética dá lugar a antinomias 'racionais', 'naturais' ou 'fatais' entre o indivíduo e a sociedade (ou ‘o mundo’), antinomias que se resolvem ou pela preponderância concedida à sociedade ou pela preeminência atribuída ao indivíduo.

Uma outra confusão, consequência da primeira, consiste ou em assimilar as formas sociais singulares às normas universais, ou a reduzi-las à mentalidade dos indivíduos. No primeiro caso, trata-se de uma concepção tradicionalista, autoritária, que vê na ordem estabelecida uma positividade e uma verdade intocáveis. No segundo caso, encontra-se o psicologismo ou espiritualismo, os quais pretende que todos os fenômenos sociais sejam imaginários, e que valha mais 'modificar o homem' antes de pensar em mudar a ordem social.

A escola é, então, uma instituição organizada que contém em si dimensões maiores, universais; menores, particulares; e organizacionais. É uma síntese dialética processada a partir dessas três dimensões num movimento de negatividade.

Ao analisar o modo como o complexo e polissêmico conceito de instituição é tomado em diferentes autores, Lourau (1996) permite que se percebam suas diferenças ao tratar o papel e a posição dos momentos universal, singular e particular, diferenças que farão com que a instituição seja percebida como mais estabelecida, estática ou instituída ou estando mais dinâmica, em permanente construção e instituinte.

Hegel, por exemplo, pauta-se na filosofia do direito e supervaloriza o momento universal. Acredita que o Estado funda as instituições por meio do direito objetivo, validando suas existências, e as instituições, por sua vez, atuariam dirigindo-se para fins universais. Trata a instituição numa perspectiva a-histórica por não considerar os movimentos sociais, políticos e, inclusive de luta, que estiveram associados à fundação do próprio Estado e da estrutura jurídica. O momento universal representaria uma verdade objetiva/positiva e viria primeiro (visão idealista), e a ação do momento particular (negatividade dos sujeitos) a ele se oporia de forma direta (sem mediação). Os sujeitos particulares buscariam incorporar as ideias universais sem que houvesse uma intencionalidade política. O momento singular, por sua vez, seria produzido pelo encontro entre universal e particular, configurando-se apenas como uma projeção da universalidade, como uma materialização do Estado na sociedade civil. A visão de Hegel sobre as instituições a situa numa condição maior de estabilidade, já que a grande força instituinte emanaria do Estado.

A concepção hegeliana de instituição é criticada pelos marxistas, os quais consideram que sua dialética - que tem a ideia (universal) como ponto de partida, numa consciência abstrata e ideal - precisaria ser virada “de cabeça para baixo”, invertida, a fim de que o ponto de partida se tornasse a realidade, a história da natureza e da humanidade.

Consequentemente, em termos institucionais, criticam a separação estabelecida por Hegel entre os interesses do Estado (universal) e sociedade civil (particular), e o fato de que o Estado passa a depender da burocracia para existir:

[...] a universalidade é confiscada pelo 'Estado real' (o poder da classe dominante) e pelo ‘Estado imaginário’ (a burocracia). Noutras palavras, o momento da singularidade, em que normalmente a universalidade deveria encarnar-se para e pela mediação do momento da particularidade, é esvaziado de seu conteúdo institucional em proveito da 
'organização supostamente racional da burocracia’, que não é outra coisa senão a administração dos homens. $\mathrm{O}$ conceito de instituição parece esvaziado de seu conteúdo. (LOURAU,1996, p. 76)

A crítica marxista auxilia a identificar as diferenças de posição. Em seu modo de abordar a questão, Marx e Engels consideram a instituição como um elemento superestrutural da infraestrutura econômica. As instituições - dentre elas a escola - seriam essencialmente formas estruturais (ênfase ao momento singular) que funcionariam ligadas à economia capitalista ocultando as relações de produção e justificando a existência das classes dominantes. Para Engels (apud LOURAU, 1996, p. 80), “as instituições são 'efeitos' do modo de produção. São determinadas pelo trabalho e pela família”.

Se há em Hegel uma supervalorização do momento universal, pode-se afirmar que a abordagem marxista estabelece uma supervalorização do momento singular, na medida em que a análise histórica das relações de classe e produção é feita por meio das estruturas singulares da economia e da sociedade:

As instituições [...] aparecem [...] como [...] formas singulares tomadas nas relações de força, de classes e de produção. $\mathrm{O}$ momento da universalidade aparece como o momento ideológico: a ‘ideia’ de Hauriou [...] [que permite] apreender a função simbólica das instituições, mas não a totalidade das funções objetivamente desempenhadas pelas instituições. Quanto ao momento da particularidade, o marxismo encarrega-se sucessivamente de pô-lo em relevo e de esquecê-lo. Hipostasiados enquanto agentes históricos, construtores de sua própria história, os indivíduos correm o risco de perder esta autonomia e iniciativa instituinte a partir do momento em que o marxismo, deixando-se levar pelas facilidades dogmáticas do economismo e do filosofismo materialista, torna-se institucional. (LOURAU, 1996, p. 141)

Também em Marx, como em Hegel, a instituição é muito mais instituída do que instituinte, muito mais forjada e estabelecida do que em movimento, condição que resulta da supervalorização da estrutura econômica e jurídica/momento singular.

Há ainda outra (e não última) forma de análise que, diante dos momentos universal, singular e particular, atua supervalorizando o terceiro: o particular. Lourau (1996, p. 140) aponta que é especialmente em abordagens fenomenológicas e psicologistas que se encontra uma supervalorização da natureza humana. Subtrai-se da dimensão humana seu caráter político e desconsidera-se o momento singular, tomado apenas como uma assimilação do momento universal: “[...] a instituição acaba por não ser mais do que uma modalidade psicológica, a interiorização das normas."

O reconhecimento da dissociação dos momentos da instituição permite compreender, então, que as instituições são, ao mesmo tempo, instituídas e instituintes, compondo uma totalidade no seio de uma totalidade maior:

O que é específico da totalidade institucional é que a diferenciação, própria de todo 'organismo', não é funcional - dependendo de uma espécie de divisão do trabalho social, determinada por uma hierarquia das 'necessidades' sociais. Esta diferenciação é simbólica: a todo momento, uma parte da instituição (um 'órgão') representa a totalidade, age para ela e é comandada por ela. Compreende-se, então, que 'a lei da relação dos órgãos institucionais entre si e com a instituição' seja a da isonomia, da troca absolutamente recíproca. Se uma parte da instituição, ou o todo, passasse à frente de alguma outra parte, não haveria mais instituição, mas burocracia. 
A posição dos 'órgãos' (ou melhor, das instâncias) na estrutura institucional não sugere somente uma topologia institucional, mas também uma dinâmica institucional. Estas instâncias não são encaixadas umas nas outra como os 'serviços' de uma organização. Estão em movimento umas em relação às outras, em relação ao todo (a 'instituição é uma coisa que se mexe'). Este movimento é produto de uma 'energia social' e produz uma 'energia institucional', isto é, a conservação do instituído e, pela discussão do instituído, a capacidade instituinte. Há um 'trabalho' da instituição, assim como há uma tendência à imobilidade [...] na burocracia. Quando 'servem' verdadeiramente, as instituições ‘trabalham'. (LOURAU, 1996, p. 64)

Universal, singular e particular constituem a instituição que só pode ser compreendida enquanto totalidade. A totalidade institucional situa-se, por sua vez, na totalidade social e traz em si suas marcas porque produz modelos de comportamento e mantêm mantém normas sociais cuja função maior é a continuidade do sistema total - o capitalismo:

Toda sua organização e os defeitos de funcionamento da organização têm como sistema de referência real, e não imaginário, esta instituição quase sagrada do modo de produção capitalista, que é a mais-valia. Do mesmo modo, a escola tem por funções preparar para a vida profissional, fornecer uma cultura geral etc.; mas tem antes de tudo por função fazer interiorizar as normas oficiais do trabalho explorado, da família cristã, do estado burguês. Na escola aprende-se também a interiorizar o modelo da fábrica. Na escola, na fábrica, o que o indivíduo aprende é a 'esmagar-se’ diante dos superiores, e em seguida, ou dado o caso, nela se aprende um ofício. (LOURAU, 1996, p. 12-13)
Todavia, a relação da totalidade institucional com a totalidade social é, também, de negatividade, o que significa que ao mesmo tempo que recebe sua influência a instituição atua sobre ela com negatividade, como uma unidade negativa, reproduzindo parte das funções ou modelos sociais e negando ou contradizendo outras. O desconhecimento dessa relação, também dialética, entre a unidade institucional/totalidade institucional e a totalidade social não permitiria compreender a escola como instituição instituinte e levaria a entendê-la apenas como instituída pelo sistema social maior, obscurecendo sua capacidade dialética e dinâmica de subversão, negatividade e contradição, capacidade que lhe garante a condição de não apenas reproduzir, mas também de produzir determinadas relações sociais.

As instituições são construções históricas e humanas, constituídas de elementos ideológicos (ideias), econômicos (estrutura e funcionalidade) e políticos (ação humana intencional), sendo, portanto, instâncias instituintes e capazes de constituir-se como realidade própria e de influenciar a realidade social.

\section{Referências}

ALARCÃO, I. (Org.). Escola reflexiva e nova racionalidade. Porto Alegre: ArtMed, 2001.

Professores reflexivos em uma escola reflexiva. São Paulo: Cortez, 2003.

ARDOINO, Jacques; LOURAU, René. As pedagogias institucionais. São Carlos: RiMa, 2003. 
CÂNDIDO, Antônio. A estrutura da escola. In: PEREIRA, l.; FORACCHI, M. M. (Orgs.). Educação e sociedade. São Paulo: Editora Nacional, 1973.

FORQUIN, Jean-Claude. Escola e cultura: as bases sociais e epistemológicas do conhecimento escolar. Porto Alegre: Artes Médicas, 1993.

GOMES, C. A escola de qualidade para todos. Revista Ensaio, Rio de Janeiro, v. 13, n. 48, p. 281- 306, jul./set. 2005.

HOUAISS, Antônio. VILLAR, Mauro de Salles. Dicionário Houaiss da língua portuguesa. Rio de Janeiro: Objetiva, 2004.

LAPASSADE, Georges; LOURAU, René. Chaves da sociologia. Rio de Janeiro: Civilização Brasileira, 1972.

LOURAU, René. A análise institucional. Petrópolis: Vozes, 1996.

PÉREZ GÓMEZ, A. I. A cultura escolar na sociedade neoliberal. Porto Alegre: ArtMed, 2001.

SCHMIDT, L. M. A desconhecida dinâmica da escola. In: RIBAS, M. H. (Org.). Formação de professores: escolas, práticas e saberes. Ponta Grossa: Ed. UEPG, 2005.

TARDIF, M.; LESSARD, C. O trabalho docente: elementos para uma teoria da docência como profissão de interações humanas. Petrópolis: Vozes, 2005.

Enviado em: 03/10/2011

Aceito em: 11/11/2011 